\title{
Assessing the aggregation behaviour of iron oxide nanoparticles under relevant environmental conditions using a multi-method approach
}

\author{
Laura Cheklia,b, Sherub Phuntsho ${ }^{\mathrm{a}}$, Maitreyee Royc, Enzo Lombi ${ }^{\mathrm{d}}$, Erica Donner ${ }^{\mathrm{b}, \mathrm{d}}$ and Ho Kyong \\ Shon ${ }^{\mathrm{a}, \mathrm{b}, *}$
}

aSchool of Civil and Environmental Engineering, University of Technology, Sydney (UTS), Post Box 129, Broadway, NSW 2007, Australia.

${ }^{b}$ CRC CARE, PO Box 486, Salisbury, SA 5106, Australia

'National Measurement Institute Australia, Department of Industry, Innovation, Science, Research and Tertiary Education PO Box 264, Lindfield NSW 2070, Australia

${ }^{\mathrm{d} C e n t r e ~ f o r ~ E n v i r o n m e n t a l ~ R i s k ~ A s s e s s m e n t ~ a n d ~ R e m e d i a t i o n, ~ U n i v e r s i t y ~ o f ~ S o u t h ~ A u s t r a l i a, ~ B u i l d i n g ~}$ X, Mawson Lakes Campus, SA 5095, Australia

*Corresponding author: Email: Hokyong.Shon-1@uts.edu.au

\section{Abstract}

Iron nanoparticles are becoming increasingly popular for the treatment of contaminated soil and groundwater; however, their mobility and reactivity in subsurface environments are significantly affected by their tendency to aggregate. Assessing their stability under environmental conditions is crucial for determining their environmental fate. A multi-method approach (including different sizemeasurement techniques and the DLVO theory) was used to thoroughly characterise the behaviour of iron oxide nanoparticles ( $\mathrm{Fe}_{2} \mathrm{O}_{3} \mathrm{NPs}$ ) under environmentally relevant conditions. Although recent studies have demonstrated the importance of using a multi-method approach when characterising nanoparticles, the majority of current studies continue to use a single-method approach.

Under some soil conditions (i.e. $\mathrm{pH} 7,10 \mathrm{mM} \mathrm{NaCl}$ and $2 \mathrm{mM} \mathrm{CaCl}_{2}$ ) and increasing particle concentration, $\mathrm{Fe}_{2} \mathrm{O}_{3} \mathrm{NPs}$ underwent extensive aggregation to form large aggregates ( $>1 \mu \mathrm{m}$ ). Coating the nanoparticles with dissolved organic matter (DOM) was investigated as an alternative "green" solution to overcoming the aggregation issue instead of using the more commonly proposed polyelectrolytes. At high concentrations, DOM effectively covered the surface of the $\mathrm{Fe}_{2} \mathrm{O}_{3} \mathrm{NPs}$, thereby conferring negative surface charge on the particles across a wide range of $\mathrm{pH}$ values. This provided electrostatic stabilisation and considerably reduced the particle aggregation effect. DOMcoated $\mathrm{Fe}_{2} \mathrm{O}_{3} \mathrm{NPs}$ also proved to be more stable under high ionic strength conditions. The presence of $\mathrm{CaCl}_{2}$, however, even at low concentrations, induced the aggregation of DOM-coated $\mathrm{Fe}_{2} \mathrm{O}_{3} \mathrm{NPs}$, mainly via charge neutralisation and bridging. This has significant implications in regards to the reactivity and fate of these materials in the environment.

Keywords: Iron oxide, Nanoparticles, Aggregation, Flow Field-Flow Fractionation, DLVO Theory, Surface coating. 


\section{Introduction}

Manufactured nanoparticles (MNPs) are defined as intentionally engineered materials with at least one dimension in the 1-100 $\mathrm{nm}$ size range (Lead and Wilkinson 2006). Due to their small size, they have often been shown to display improved catalytic, chemical, optical, mechanical, electronic and magnetic properties over conventional micro/macroscale particles (Jortner and Rao 2002). Over recent decades, some MNPs have attracted increasing attention due to their potential efficacy in the treatment of contaminated soil and groundwater (Crane and Scott 2012).

Due to their low cost, highly reactive surface sites and high in-situ reactivity, the most widely studied engineered nanoparticles for soil and groundwater remediation are nanoscale zero-valent iron (nZVI) nanoparticles (Wang and Zhang 1997; Elliott and Zhang 2001; Zhang 2003). Numerous studies have shown that the nanoparticles are highly effective for the removal/degradation or stabilisation of a wide range of common environmental contaminants including chlorinated organic solvents (Elliott and Zhang 2001; Zhang 2003), organic dyes (Liu et al. 2005), various inorganic compounds (Alowitz and Scherer 2002), and even some metals (Kanel et al. 2005). In the past few years, a variety of iron oxide nanoparticles have also been investigated for environmental remediation purposes. Despite the potential efficacy of these materials, many laboratory and pilot-scale field studies have demonstrated that the mobility and reactivity of iron-based nanoparticles are substantially limited in natural porous systems (e.g. soils and groundwater aquifers) (Schrick et al. 2004; Quinn et al. 2005; He and Zhao 2007; Saleh et al. 2007). Aggregation is considered to be the primary cause of reduced mobility and reactivity, and this phenomenon is the result of many factors including solution $\mathrm{pH}$, ionic strength and the presence of organic matter (Ponder et al. 2000; Saleh et al. 2005). In the case of iron-based nanoparticles, previous studies have investigated that these nanoparticles have $\mathrm{pH}-$ dependant surface charges and that extensive aggregation due to charge neutralisation occurs near the point of zero charge (PZC) (Sun et al. 2006; Baalousha et al. 2008; Baalousha 2009; Hu et al. 2010). Furthermore, soil and groundwater conditions are often characterised by high ionic strength and high concentrations of monovalent (e.g., $\mathrm{Na}^{+}, \mathrm{K}^{+}$) and divalent (e.g., $\mathrm{Ca}^{2+}, \mathrm{Mg}^{2+}$ ) cations in the $\mathrm{mM}$ range; factors that are known to reduce electrostatic repulsion between particles and thereby enhance aggregation (Saleh et al. 2008).

To optimise the use of MNPs for environmental remediation it is necessary to understand the factors that cause aggregation under environmentally relevant conditions with the aim of enhancing their mobility while still maintaining good reactivity (Saleh et al. 2007). Surface modifications using charged polymers, polyelectrolytes or surfactants are now widely used to disperse nanoparticles in environmental matrices such as soil and water (Zhang et al. 1998; Schrick et al. 2004; Saleh et al. 2005; He et al. 2007; Saleh et al. 2007; Hajdú et al. 2009; Phenrat et al. 2009; Sirk et al. 2009; Cirtiu et al. 2011). These modifications can theoretically provide both electrostatic and steric (so-called electrosteric) stabilisation to prevent particles from aggregating and can also reduce the propensity for surface attachment (Saleh et al. 2005; Saleh et al. 2008). Unfortunately, although these different surface coatings can enhance nanoparticle stability, they can also be expensive, have toxic effects on the environment, and alter the interaction of MNPs with contaminants (Tiraferri et al. 2008). Natural surface coating by the adsorption of dissolved organic matter (DOM) such as humic and fulvic acids on the surface of nanoparticles has also been studied as an alternative "green" surface coating, and has been demonstrated to enhance nanoparticle stability through electrosteric stabilisation (Mylon et al. 2004; Illes and Tombácz 2006; Hu et al. 2010). The advantage of DOM over conventional 
surface modifiers is that DOM is ubiquitous in the environment, cheap, non-toxic, and not only has the ability to adsorb onto metal oxide nanoparticles but is also able to complex with heavy metals (Liu et al. 2008; Dickson et al. 2012). A recent study by Chen et al. (Chen et al. 2011) demonstrated that DOM-coated nZVI may significantly mitigate bacterial toxicity due to the electrosteric hindrance preventing direct contact.

In this study, characterisation of bare $\mathrm{Fe}_{2} \mathrm{O}_{3} \mathrm{NPs}$ and the aggregation behaviour of these nanoparticles under relevant environmental conditions (i.e. $\mathrm{pH}$, particle concentration and ionic strength) were performed using flow field-flow fractionation (FIFFF), dynamic light scattering (DLS) and scanning electron microscopy (SEM). Although the characterisation of MNPs can be considerably simpler than it is for natural particle samples, MNPs are also complex, and a multiple characterisation approach is necessary to ensure the accuracy of the characterisation data (Lead and Wilkinson 2006; Domingos et al. 2009). In fact, due to analytical challenges, the lack of appropriate characterisation data in environmentally realistic conditions is a major limitation of current research in this area. As such, there is clearly a need for useful characterisation tools that can assist in assessing MNP behaviour under relevant environmental conditions. Flow field-flow fractionation (FIFFF) is well suited to measuring MNP behaviour under relevant conditions simply by modifying the mobile phase used during characterisation. However, one of the main limitations of FIFFF is related to material losses during analysis. These generally occur via particle-membrane interaction and adsorption and may represent up to $50 \%$ of the injected mass (Hassellöv and Kaegi 2009). The particle-membrane interaction is mainly due to attractive forces (e.g. Van der Waals), hydrophobic and charge interactions which are all dependent on the mobile phase characteristics.

This is the first time that FIFFF has been applied to study the aggregation behaviour of $\mathrm{Fe}_{2} \mathrm{O}_{3} \mathrm{NPs}$ under relevant environmental conditions. The results have been compared with those from other size-measurement techniques and theoretical models to provide increased confidence in the outcomes. The stability of the DOM-coated $\mathrm{Fe}_{2} \mathrm{O}_{3} \mathrm{NPs}$ was also assessed under relevant conditions using FIFFF and DLS. Although many studies have demonstrated that DOM-coated $\mathrm{Fe}_{2} \mathrm{O}_{3} \mathrm{NPs}$ can be stable under a wide range of $\mathrm{pH}$ and $\mathrm{NaCl}$ concentrations, there is a lack of data in regard to the effect of divalent cations, especially $\mathrm{Ca}^{2+}$, which is known to complex easily with organic matter (Hong and Elimelech 1997).

The results of this study are also relevant to the aggregation behaviour of $n Z \mathrm{VI}$, as $\mathrm{nZVI}$ particles have been shown to have substantial shells of iron oxide (Phenrat et al. 2007). Therefore, $\mathrm{Fe}_{2} \mathrm{O}_{3} \mathrm{NPs}$ demonstrate various similar properties to $\mathrm{nZVI}$ when they are used to treat contaminated soil and groundwater and can thus be used as a model system for understanding aggregation behaviour (He et al. 2008).

\section{Theoretical method: The DLVO theory}

The Derjaguin-Landau-Verwey-Overbeek (DLVO) theory (Derjaguin and Landau 1941; Verwey 1947; Verwey and Overbeek 1948) was employed in this study to model the interactions between $\mathrm{Fe}_{2} \mathrm{O}_{3} \mathrm{NPs}$ at different particle concentrations, $\mathrm{pH}$ and ionic strength. This theory provides the classical explanation for the stability of colloids in suspension. It states that the stability of nanoparticles can be explained by the sum (i.e. total interaction energy) of the van der Waals attractive forces $\left(V_{v d w}\right)$ and the electrostatic repulsive forces $\left(V_{e l}\right)$. The total interaction energy $\left(V_{T}\right)$ is 
experienced by a nanoparticle when approaches another particle, and determines whether the net interaction between the particles is repulsive or attractive (Zhang et al. 2008; Dickson et al. 2012).

DLVO calculations were performed according to the equations described in (Elimelech et al. 1998)):

$V_{v d w}=\frac{-A}{6}\left[\frac{2 R^{2}}{h(4 R+h)}+\frac{2 R^{2}}{(2 R+h)^{2}}+\ln \frac{h(4 R+h)}{(2 R+h)^{2}}\right]$

$V_{e l}=2 \pi \varepsilon R \delta^{2} \ln \left[1+e^{-k h}\right]$

$V_{T}=V_{v d w}+V_{e l}$

where $A(\mathrm{~J})$ is the Hamaker constant $\left(1.10^{-9} \mathrm{~J}\right.$ for iron nanoparticles (Phenrat et al. 2009)); $R(\mathrm{~m})$ is the radius of particles; $h(\mathrm{~m})$ is the distance between the surfaces of two interacting particles; $\varepsilon=\varepsilon_{r} \varepsilon_{0}$ is the dielectric constant where $\varepsilon_{r}\left(78.54\right.$ for water at $\left.25^{\circ} \mathrm{C}\right)$ is the relative dielectric constant of the medium and $\varepsilon_{0}\left(8.85 .10^{-12} \mathrm{C}^{2} / \mathrm{J} . \mathrm{m}\right)$ is the permittivity in vacuum; $\delta$, the zeta potential of the charged particles; $k(1 / \mathrm{m})$ is the reciprocal of the thickness of the double layer with $k=2.32 \times 10^{9}\left(\Sigma C_{i} Z_{i}^{2}\right)^{1 / 2}$ where $C_{i}$ is the concentration of ion, $i$, and $Z_{i}$ is its valency value.

The following assumptions/measurements are used in this study:

(1) Particle diameter is $30 \mathrm{~nm}$ (average size of the primary particles provided by Sigma Aldrich).

(2) When not specified, ionic strength is assumed to be $1 \mathrm{mM} \mathrm{NaCl}$. In fact, when no electrolytes are used (i.e. when using ultrapure water), equation 2 is reduced to zero and calculations cannot be performed.

(3) Zeta potentials are experimentally determined.

\section{Materials and analytical methods}

\subsection{Chemicals and reagents}

Commercially available $\mathrm{Fe}_{2} \mathrm{O}_{3} \mathrm{NPs}\left(\alpha-\mathrm{Fe}_{2} \mathrm{O}_{3}\right.$, average particle size $30 \mathrm{~nm}$, BET 50-245 m²/g, $20 \mathrm{wt}$ \% dispersed in water at $\mathrm{pH} 4$ ), humic acid (HA) (technical grade), $\mathrm{NaCl}$ and $\mathrm{CaCl}_{2}$ (99.99\% purity) were all supplied by Sigma-Aldrich Australia. HA was employed as a surrogate DOM since HA and more generally humic substances represent an important fraction of DOM in soils, surface and groundwater (Aiken et al. 1985) and have been demonstrated to play a key role in water quality for various pollutants such as trace metals and some organic compounds (Murphy et al. 1990; Maurice and Namjesnik-Dejanovic 1999).

\subsection{Sample preparation}

$\mathrm{Fe}_{2} \mathrm{O}_{3} \mathrm{NPs}$ were suspended in ultrapure water to obtain a set of solutions in the range $10-200 \mathrm{mg} / \mathrm{L}$ at $\mathrm{pH} 4 \pm 0.1$. Solution $\mathrm{pH}$ was adjusted using $0.1 \mathrm{M} \mathrm{HCl}$ and $0.1 \mathrm{M} \mathrm{NaOH}$ solutions and left for 24 hours to equilibrate, after which the $\mathrm{pH}$ was re-measured and adjusted if necessary for all experiments. No 
buffers were used in this study because they usually have a high ionic strength and thus may alter the surface chemistry of the $\mathrm{Fe}_{2} \mathrm{O}_{3}$ NPs and enhance their aggregation (Baalousha 2009).

HA was dissolved in ultrapure water with a resistivity of $18 \mathrm{M} \Omega / \mathrm{cm}$ (MilliQ, Millipore, USA) to obtain a stock solution with a concentration of $500 \mathrm{mg} / \mathrm{L}$. This was then filtered through a $0.45 \mu \mathrm{m}$ filter using vacuum suction to retain only the 'dissolved' organic matter, and stored at $4^{\circ} \mathrm{C}$ prior to experimental use. The total organic content (TOC) of the stock solution (dilution 1:10) was measured as $19.1 \mathrm{mgC} / \mathrm{L}$ using a TOC analyser (TOC-VCPH, TNM-1, Shimadzu, Japan).

HA-coated $\mathrm{Fe}_{2} \mathrm{O}_{3} \mathrm{NPs}$ were prepared by mixing $10 \mathrm{~mL}$ of concentrated $\mathrm{Fe}_{2} \mathrm{O}_{3} \mathrm{NPs}$ (i.e. $2 \mathrm{~g} / \mathrm{L}$ ) with either 1, 2, 4, 10 or $20 \mathrm{~mL}$ of HA (initial concentration of the stock solution: $500 \mathrm{mg} / \mathrm{L}$ ) for one hour before diluting in ultrapure water to obtain five solutions with $\mathrm{Fe}_{2} \mathrm{O}_{3} \mathrm{NP}$ concentration of $200 \mathrm{mg} / \mathrm{L}$ and $\mathrm{HA}$ concentration of $5,10,20,50$ and $100 \mathrm{mg} / \mathrm{L}$. All solutions were then brought to $\mathrm{pH} 4 \pm 0.1$ using either $0.1 \mathrm{M} \mathrm{HCl}$ or $0.1 \mathrm{M} \mathrm{NaOH}$ and stored at $4^{\circ} \mathrm{C}$ for 24 hours before measurements were taken.

$\mathrm{NaCl}$ and $\mathrm{CaCl}_{2}$ were also dissolved in ultrapure water to obtain stock solutions with a concentration of $500 \mathrm{mM}$. The stock solutions were filtered through a $0.45 \mu \mathrm{m}$ filter using vacuum suction to avoid dust contamination before being used as the mobile phase in FIFFF experiments or to prepare samples for FIFFF and DLS measurements.

\subsection{FIFFF Analysis}

FIFFF is a chromatography-like separation technique based on laminar flow (so-called channel flow) in a very thin (i.e. $\sim 250 \mu \mathrm{m}$ ) channel with a cross flow applied perpendicular to the channel flow. The channel flow has a parabolic velocity profile (i.e. the maximum velocity is at the centre of the channel). The cross flow forces the particles to move toward a membrane at the channel wall, from where they can move back into the channel as a result of diffusion forces in the normal elution mode (i.e. for particles smaller than $1 \mu \mathrm{m}$ ). The smallest particles, having the highest diffusion coefficient, will migrate farther into the channel at higher flow rates and will thus elute first. The theory and principles of FIFFF can be found elsewhere (Giddings 2000; Phuntsho et al. 2011).

Two different FIFFF systems were used in this study. One was an asymmetrical AF2000 Focus (FIFFFa) (Postnova Analytics, Germany) with channel length of $29.8 \mathrm{~cm}$ (tip to tip), channel width of $2 \mathrm{~cm}$ and channel thickness of $0.025 \mathrm{~cm}$. The detection system comprised a UV/Vis detector operating at a 254 $\mathrm{nm}$ wavelength (SPD 20A from Shimadzu, Japan). The software AF2000 Control, version 1.1.0.23 (Postnova Analytics) was used to control the FIFFF system. A regenerated cellulose membrane (ZAF4-MEM-612-10KD, Postnova Analytics, Germany) with a molecular weight cut-off of $10 \mathrm{kDa}$ was used as a channel wall. Sodium azide $\left(0.1 \mathrm{mM} \mathrm{NH}_{3}\right)$ was used as bactericide in the mobile phase for all experiments. The sample volumes were all $20.8 \mu \mathrm{L}$ and were injected using $50 \mu \mathrm{L}$ sample loop (Rheodyne Corporation, CA, USA); at least three independent replicates were run per sample and the data averaged. In general, good agreement was observed between replicates (i.e. peak heights differing by less than $5 \%$ ). The final solution concentration of $\mathrm{Fe}_{2} \mathrm{O}_{3} \mathrm{NPs}$ for all FIFFF/UV experiments was $50 \mathrm{mg} / \mathrm{L}$ for the aggregation study and $200 \mathrm{mg} / \mathrm{L}$ for the DOM coating stability study to give satisfactory separation and detection. These concentrations are necessary to ensure suitable 
detection by UV detectors because the sample becomes considerably diluted in the FIFFF channel during the elution stage.

The second FIFFF system (FIFFFb), used only for the pH effect study, consisted of an Eclipse 3+ system (Wyatt Technology, Dernbach, Germany) with channel length of $26.55 \mathrm{~cm}$ (tip to tip) and channel thickness of $0.035 \mathrm{~cm}$, equipped with an Agilent $1200 \mathrm{HPLC}$ system (Agilent technologies, Santa Clara, CA, USA). The Agilent 1200 HPLC system comprised an in-line degasser and an autosampler for the delivery of the carrier liquid and the injection of samples. A regenerated cellulose membrane (Millipore PLGC, 10KD, Wyatt Technology, Dernbach, Germany) with a molecular weight cut-off of $10 \mathrm{kDa}$ was used as a channel wall. The on-line detection system for eluted particles consisted of a UV/Vis absorbance diode array detector (DAD1200, Agilent Technologies) with a spectral range from $190 \mathrm{~nm}$ to $950 \mathrm{~nm}$ and a quasi-elastic light scattering detector (QELS, Dawn HELEOS II, Wyatt Technology Corporation, Santa Barbara, CA) operating at a wavelength of $658 \mathrm{~nm}$. The software ChemStation, version B.04.02 SP1 (Agilent Technology) was used to control the delivery flow of the FIFFF system. Data acquisition and data processing were done using Astra, version 6.0.2 software (Wyatt Technology). The final solution concentration of $\mathrm{Fe}_{2} \mathrm{O}_{3} \mathrm{NPs}$ for all FIFFF/QELS experiments was $200 \mathrm{mg} / \mathrm{L}$ since QELS needs relatively high concentrations of particles to ensure proper detection.

\subsubsection{FIFFF Calibration Curves}

Latex beads of $22 \mathrm{~nm}, 58 \mathrm{~nm}, 100 \mathrm{~nm}$ and $410 \mathrm{~nm}$ were used to create calibration curves from which hydrodynamic diameters of $\mathrm{Fe}_{2} \mathrm{O}_{3} \mathrm{NPs}$ were determined. These curves correlate the retention time to particle size. Calibration curves were established for all mobile phases and conditions (change in cross flow or channel flow) used in this study and regularly (i.e. once a week) re-drawn to check the accuracy of sizing. An example of the calibration curves used for the $\mathrm{pH}$ effect study can be found in Figure S1.

\subsection{2 pH Effect}

To investigate the effect of $\mathrm{pH}$ on the aggregation of $\mathrm{Fe}_{2} \mathrm{O}_{3} \mathrm{NPs}$ samples of $50 \mathrm{mg} / \mathrm{L}$ of NPs were $\mathrm{pH}$ adjusted then equilibrated for 24 hours prior to analysis. The mobile phase consisted of ultrapure water prepared at different $\mathrm{pH}$ values ranging from $\mathrm{pH} 3$ to $\mathrm{pH} 10$. This is the range of $\mathrm{pH}$ tolerance for the FFF membrane; outside this range the membrane may be altered. For pH 2, 11 and 12, only DLS measurements were performed. The FIFFF measurement conditions are summarised in Table 1.

\subsubsection{Ionic Strength Effect}

The effect of $\mathrm{Na}^{+}$and $\mathrm{Ca}^{2+}$ on $\mathrm{Fe}_{2} \mathrm{O}_{3} \mathrm{NPs}$ aggregation was investigated as follows. $\mathrm{NaCl}$ and $\mathrm{CaCl}_{2}$ solutions were prepared at $1 \mathrm{mM}, 5 \mathrm{mM}$ and $10 \mathrm{mM}$, and $0.5 \mathrm{mM}$ and $2 \mathrm{mM}$, respectively, by diluting the $500 \mathrm{mM}$ stock solutions using ultrapure water and adjusting to $\mathrm{pH} 4$ before being used as the mobile phase. $\mathrm{Fe}_{2} \mathrm{O}_{3} \mathrm{NPs}$ samples of $50 \mathrm{mg} / \mathrm{L}$ were suspended in solutions having the same ionic strength as the different mobile phase solutions (i.e. $1 \mathrm{mM}, 5 \mathrm{mM}$ and $10 \mathrm{mM} \mathrm{NaCl}$ and $0.5 \mathrm{mM}$ and $2 \mathrm{mM} \mathrm{CaCl}_{2}$ ) and equilibrated for 24 hours before measurements. These ions were chosen because they are abundantly present in soil and in groundwater aquifers in this typical concentration range (Saleh et al. 2008). The operating conditions are presented in Table 1. 


\subsubsection{Stability of DOM-coated $\mathrm{Fe}_{2} \mathrm{O}_{3} \mathrm{NPs}$}

HA-coated $\mathrm{Fe}_{2} \mathrm{O}_{3} \mathrm{NPs}$ at five different $\mathrm{HA}$ concentrations were analysed by FIFFF for size determination using ultrapure water at $\mathrm{pH} 4$ as the mobile phase. The operating conditions are displayed in Table 1.

The most stable DOM-coated $\mathrm{Fe}_{2} \mathrm{O}_{3} \mathrm{NPs}$ (i.e. mixture of $50 \mathrm{mg} / \mathrm{L} \mathrm{HA}$ and $200 \mathrm{mg} / \mathrm{L} \mathrm{Fe}_{2} \mathrm{O}_{3} \mathrm{NPs}$ ) were then tested under environmentally relevant conditions by modifying the mobile phase and the solution where the particles were suspended (i.e. $\mathrm{pH} 7,10 \mathrm{mM} \mathrm{NaCl}$ and $0.5 \mathrm{mM} \mathrm{CaCl}_{2}$ ). The operating conditions are summarised in Table 1.

A solution of $100 \mathrm{mg} / \mathrm{L}$ of HA was also analysed by FIFFF for molecular weight determination using sodium salt of Polystyrene sulfonates-PSS (Polysciences, Inc., PA, USA) of four different molecular weights $(4600,8000,18000$ and $35000 \mathrm{Da}$, as provided by the manufacturer, with a polydispersity of 1.1) to create a calibration curve (see Figure S2). The operating conditions were $0.5 \mathrm{~mL} / \mathrm{min}$ for the channel flow and $3 \mathrm{~mL} / \mathrm{min}$ for the cross flow.

Table 1

\subsection{DLS analysis}

A Zetasizer (model ZEN3600; Malvern Instruments, Worcestershire, UK) operating with a He-Ne laser at a wavelength of $633 \mathrm{~nm}$ was used to determine the zeta potential and hydrodynamic diameter of the different samples. Physical principles, mathematical treatment, and limitations of the DLS data can be found elsewhere (Filella et al. 1997). Samples used in DLS experiments were the same as for FIFFF experiments to ensure data comparability except for the study of concentration effect.

\subsubsection{Concentration Effect}

Five solutions of $\mathrm{Fe}_{2} \mathrm{O}_{3} \mathrm{NPs}$ were prepared at pH 3 with concentrations of 10, 20, 50,100 and 200 $\mathrm{mg} / \mathrm{L}$. The $\mathrm{pH}$ was raised slowly from $\mathrm{pH} 3$ to 5 by adding drops of $0.1 \mathrm{M} \mathrm{NaOH}$, and the Z-average hydrodynamic diameter was measured without further modifications. The $\mathrm{pH}$ was then brought directly to $\mathrm{pH} 10$ to overcome the aggregation occurring around the $\mathrm{PZC}$, before being raised slowly to $\mathrm{pH} 12$. Finally, solutions were brought from $\mathrm{pH} 9$ to 6 by adding drops of $0.1 \mathrm{M} \mathrm{HCl}$.

\subsection{Scanning Electron Microscopy (SEM) analysis for the effect of $\mathrm{pH}$}

Silicon wafers attached on carbon stubs were used for SEM measurements. About $10 \mu \mathrm{L}$ of sample was deposited on a silicon wafer and left to dry completely. Images were obtained from a Zeiss Supra 55VP variable pressure SEM (Carl Zeiss AG, Germany) and recorded using SmartSEM ${ }^{\circledR}$ software. The mean equivalent circular diameter was determined from these images. Samples used for SEM measurements were the same as those analysed in the FIFFF and DLS experiments for the study of pH effect.

\section{Results and discussions}

\subsection{Characterisation of $\mathrm{Fe}_{2} \mathrm{O}_{3} \mathrm{NPs}$ Nanoparticles}

SEM was used to identify the general characteristics of the $\mathrm{Fe}_{2} \mathrm{O}_{3} \mathrm{NPs}$. At $\mathrm{pH} 3$, the $\mathrm{Fe}_{2} \mathrm{O}_{3} \mathrm{NPs}$ were spherical and present as single independent particles, as illustrated in Figure 1a. Analysis of 212 
particles by SEM yielded a mean equivalent circular diameter of $25 \mathrm{~nm}$ with a very low polydispersity (i.e. standard deviation: $\pm 3.5 \mathrm{~nm}$, Figure $1 \mathrm{~b}$ ).

Zeta potential measurements carried out at different particle concentrations (see Figure S3) suggested that $\mathrm{Fe}_{2} \mathrm{O}_{3} \mathrm{NPs}$ are highly positively charged at low pH values (i.e. $\mathrm{pH} 2-5$ ). The zeta potential decreased as $\mathrm{pH}$ increased from 5 to 9 and became highly negative from $\mathrm{pH} 10$ with a PZC at around $\mathrm{pH} 7$ for all particle concentrations. This value is within the range of $\mathrm{PZC}$ values (i.e. $\mathrm{pH} 6.8$ to 8.1) found in the literature for iron oxide nanoparticles (Tombácz et al. 2004; Illes and Tombácz 2006; Baalousha et al. 2008; Baalousha 2009; Hu et al. 2010).

\subsubsection{Effect of particle concentration on the aggregation behaviour of $\mathrm{Fe}_{2} \mathrm{O}_{3} \mathrm{NPs}$} $200 \mathrm{mg} / \mathrm{L}$, and different $\mathrm{pH}$ values from pH 2 to 12 (all data are presented in Supportive Table 1). It should be noted that samples with particles having Z-average hydrodynamic diameter $>1,000 \mathrm{~nm}$ were settling during the analysis; however, DLS can only be used when particles are strictly subjected to Brownian motion. Thus, these data are only indicative of the agglomeration trend and cannot be used as accurate or absolute measurements.

At all particle concentrations, maximum aggregation was reached at the PZC where the net particle surface charge was reduced to zero, as shown in Figure 2. Far from this point, particle aggregate sizes decrease because particles are stabilised by electrostatic repulsion forces.

The results also show a particle size concentration dependence at nanoparticle concentrations above $50 \mathrm{mg} / \mathrm{L}$, especially at $\mathrm{pH}>5$. This is presumably due to the fact that when particle concentration increases, the distance between the particles in the sample is reduced, which increases the chance of collision between particles and hence, their aggregation. Previous studies (Baalousha 2009; Dickson et al. 2012) indicated similar findings for this concentration range. It should be noted here that injected concentrations of $\mathrm{Fe}_{2} \mathrm{O}_{3} \mathrm{NPs}$ on contaminated sites are generally between 1 to $10 \mathrm{~g} / \mathrm{L}$ (Saleh et al. 2008), and aggregation phenomena are expected to be even more exacerbated in this high concentration range.

Figure 2

These results can also be explained by the DLVO theory. Figure 3a and 3b show the interaction forces that arise between two nanoparticles at concentrations of 10 and $200 \mathrm{mg} / \mathrm{L}$, respectively. At $10 \mathrm{mg} / \mathrm{L}$ and high $\mathrm{pH}$ values (i.e. $\mathrm{pH} \mathrm{10,11}$ and 12), a net positive energy barrier prevents particles from aggregating. Because this barrier decreases from $\mathrm{pH} 12$ to $\mathrm{pH} 10$, we observe an increase in particle aggregate sizes. However, at $200 \mathrm{mg} / \mathrm{L}$ and $\mathrm{pH} 10$, the net energy between particles is attractive which induces the aggregation of particles. At pH 11 and $\mathrm{pH} 12$, the net positive barrier, although existing, is too low to prevent the particles from aggregation.

Figure 3

\subsubsection{Effect of $\mathbf{p H}$}

The effect of $\mathrm{pH}$ on the aggregate size of $\mathrm{Fe}_{2} \mathrm{O}_{3} \mathrm{NPs}$ at a concentration of $50 \mathrm{mg} / \mathrm{L}$ is shown in 
Table 2 for FIFFFa, DLS and SEM measurements. The results for DLS and FIFFFb measurements at 200 $\mathrm{mg} / \mathrm{L}$ are reported in Table S1 and S2. The size analysis showed a good agreement among the three measurement techniques. In general, the sizes measured by SEM were comparable to FIFFFa sizes, while the sizes measured by DLS were generally larger than both FIFFFa and FIFFFb. DLS is known to be very sensitive to larger particles and a very small number of large particles (e.g. formed during the aggregation process) can induce a substantial shift toward larger sizes (Domingos et al. 2009). Moreover, it has also been demonstrated that the diffusion coefficient, from which the Z-average hydrodynamic diameter is determined, may show angular dependence and that lower angles yielded more precise values than those obtained at one angle only, which is the case with DLS (Takahashi et al. 2008).

At pH 10, a significant difference in size was observed using the SEM, FIFFF and DLS techniques; the FIFFF results in particular, were much lower than those from other techniques showing the limitation of this technique. This could be explained by the fact that, at this $\mathrm{pH}$, both the FFF membrane and $\mathrm{Fe}_{2} \mathrm{O}_{3} \mathrm{NPs}$ are negatively charged. Thus, in addition to the concentration gradient effect that drives the diffusion of particles back into the channel, electrostatic repulsive forces also arise between particles and the membrane, causing lower retention times than expected and translating into an underestimation of particle size.

Another limitation of the FIFFF techniques simulating environmental conditions is related to the recovery of the injected sample. FIFFF fractograms show that the majority of the samples are eluted in the void region (except at $\mathrm{pH} 3$ ) and only a small fraction of the injected sample (i.e. $<5 \%$ ) is detected during the elution time. This can probably be explained by the fact that when $\mathrm{pH}$ increases, some large aggregates may be formed $(>1 \mu \mathrm{m})$. These aggregates (even though not representative of the whole sample) are much larger than the rest of the sample and are eluted in the void peak in steric elution mode. To reduce the intensity of the void peak signal, pre-fractionation of the sample could be used to increase the sample concentration and recovery during the elution.

Despite differing in absolute values, size measurements by FIFFF and DLS did show similar trends. Both the hydrodynamic diameter (from FIFFF) and Z-average hydrodynamic diameter (from DLS) increased slightly from $\mathrm{pH} 3$ to 5 with the formation of doublets, triplets or larger aggregates (as illustrated by the SEM images) and then increased significantly at higher $\mathrm{pH}$ values, up to a maximum at $\mathrm{pH} 7$ (i.e. at the $\mathrm{PZC}$ ) with the formation of very large aggregates (cf. SEM image). Around the PZC, aggregation was so extensive that the samples could not be measured by FIFFF and DLS. At $\mathrm{pH}$ values above the PZC, aggregate sizes started to decrease but not at the same rate. As discussed previously, at high particle concentration (i.e. $200 \mathrm{mg} / \mathrm{L}$ ), the chance of collision is enhanced, as is the potential for aggregation due to lower interparticle repulsive forces according to the DLVO theory. However, below $50 \mathrm{mg} / \mathrm{L}$, far from the $\mathrm{PZC}$ (i.e. $\mathrm{pH} 10$ to 12 ), $\mathrm{Fe}_{2} \mathrm{O}_{3} \mathrm{NPs}$ remained stable and the average particle size became closer to the original size (i.e. as measured at pH 3).

Table 2

Figure 4 shows the DLVO energy profiles for particle-particle interactions as a function of $\mathrm{pH}$ at 50 $\mathrm{mg} / \mathrm{L}$. From $\mathrm{pH} 2$ to 7 , there is a significant decrease in the repulsive forces between particles due to the decrease in particle surface charge to zero at the PZC (cf. Figure S3). Around the PZC there is no net positive energy barrier promoting the formation of very large aggregates (i.e. up to several 
micrometres) since the only factor controlling aggregation is Brownian motion (Hu et al. 2010). At higher $\mathrm{pH}$, starting at $\mathrm{pH} 10$, the particles become highly negatively charged; giving rise to repulsive forces, and a net positive energy barrier once again prevents particles from aggregating.

Figure 4

\subsubsection{Effect of ionic strength}

Figure 5 shows the FIFFF/UV fractograms of $\mathrm{Fe}_{2} \mathrm{O}_{3} \mathrm{NPs}$ as a function of ionic strength, and Table 3 gives the corresponding hydrodynamic diameters obtained from the FFF fractograms as well as the Z-average hydrodynamic diameters obtained by DLS measurements.

The DLS results show an increase in particle aggregate sizes with increasing ionic strength. At low ionic strength ( $1 \mathrm{mM}-5 \mathrm{mM} \mathrm{NaCl}$ and $0.5 \mathrm{mM} \mathrm{CaCl}_{2}$ ), the Z-average hydrodynamic diameter varies slightly from 63.19 to $64.92 \mathrm{~nm}$. This is not significantly different from the size of nanoparticles measured in ultrapure water. This indicates that at low ionic strength, electrostatic repulsive forces are dominant over the attractive forces, preventing particles from aggregation. However, the use of $10 \mathrm{mM} \mathrm{NaCl}$ or $2 \mathrm{mM} \mathrm{CaCl}_{2}$ resulted in particle aggregation, probably due to the reduction in repulsive forces between particles as shown in Figure 6 .

The FIFFF fractograms (Figure 5) show no change in the retention times with increased ionic strength but a significant decrease in the UV signal intensity is observed. The constant elution time is expected as it has been demonstrated in previous studies that ionic strength has no effect on retention time of particles of the same size (Dubascoux et al. 2008; Shon et al. 2009).

Figure 5

However, the decrease in UV signal points to a lower recovery at higher ionic strength, which could be explained by the DLVO theory and DLS results. Figure 6 shows that increasing ionic strength leads to a significant decrease in the repulsive forces between particles, which could lead to the formation of larger particle aggregates. Dubascoux et al. (2008) explained that an increase in ionic strength leads to a decrease in the double layer thickness of particles, which promotes the formation of larger aggregates. These larger clusters of particles will be located closer to the FFF membrane which will increase the interactions between the membrane and these larger aggregates. Thus, they could be irreversibly adsorbed onto the membrane explaining the observed decrease in the UV signal.

Figure 6

\subsection{Stability of DOM-coated $\mathrm{Fe}_{2} \mathrm{O}_{3} \mathrm{NPs}$ under environmentally relevant conditions}

\subsubsection{Effect of DOM on particle charge}

Figure 7 shows the zeta potential profiles of $\mathrm{Fe}_{2} \mathrm{O}_{3} \mathrm{NPs}$ alone $(200 \mathrm{mg} / \mathrm{L}), \mathrm{HA}$-coated $\mathrm{Fe}_{2} \mathrm{O}_{3} \mathrm{NPs}$ at variable $\mathrm{HA}$ concentration and $\mathrm{HA}$ alone $(50 \mathrm{mg} / \mathrm{L})$ plotted as a function of $\mathrm{pH}$, ranging from 3 to 10 . 
At low HA concentrations (i.e. from 5 to $20 \mathrm{mg} / \mathrm{L}$ ), the zeta potential of $\mathrm{Fe}_{2} \mathrm{O}_{3} \mathrm{NPs}$ decreases, resulting in the PZC occurring at lower $\mathrm{pH}$ values (i.e. from $\mathrm{pH} 7$ for $0 \mathrm{mg} / \mathrm{L} \mathrm{HA}$ to $\mathrm{pH} 4$ for $20 \mathrm{mg} / \mathrm{L}$ $\mathrm{HA}$ ). This shift in the $\mathrm{pH}$ of the $\mathrm{PZC}$ is probably due to the adsorption of $\mathrm{HA}$ on the surface of $\mathrm{Fe}_{2} \mathrm{O}_{3} \mathrm{NPs}$ causing a change in their surface charge. The zeta potential of $\mathrm{HA}$ indicates that it is negatively charged over the whole $\mathrm{pH}$ range. This is due to the fact that HA macromolecules carry many functional groups, including carboxylic and phenolic groups (Hajdú et al. 2009; Hu et al. 2010; Dickson et al. 2012). At concentrations above $20 \mathrm{mg} / \mathrm{L}$, the zeta potential of $\mathrm{HA}$-coated $\mathrm{Fe}_{2} \mathrm{O}_{3} \mathrm{NPs}$ remained negative across the whole $\mathrm{pH}$ range tested. $\mathrm{At} \mathrm{pH}$ values greater than the $\mathrm{PZC}$ of the uncoated $\mathrm{Fe}_{2} \mathrm{O}_{3} \mathrm{NPs}$, both $\mathrm{Fe}_{2} \mathrm{O}_{3} \mathrm{NPS}$ and $\mathrm{HA}$ are negatively charged and adsorption of $\mathrm{HA}$ is not expected to occur. Thus, the decrease in zeta potential values is probably due to the increased HA concentration which brings more negative charges into solution and shifts the zeta potential downwards.

Figure 7

\subsubsection{Effect of DOM concentration on particle aggregation}

The effect of $\mathrm{HA}$ concentration on the aggregation of $\mathrm{HA}$-coated $\mathrm{Fe}_{2} \mathrm{O}_{3} \mathrm{NPs}$ was investigated by FIFFF and $\mathrm{DLS}$ (Figure $8 \mathrm{a}$ and $\mathrm{b}$ ) at $\mathrm{pH} 4$. At this $\mathrm{pH}, \mathrm{Fe}_{2} \mathrm{O}_{3} \mathrm{NPs}$ are strongly positively charged (i.e. zeta potential of $+38.5 \mathrm{mV}$, Figure 7) and $\mathrm{HA}$ is still strongly negatively charged (i.e. zeta potential of -38.8 $\mathrm{mV}$, Figure 7). As the adsorption of DOM on the surface of $\mathrm{Fe}_{2} \mathrm{O}_{3} \mathrm{NPs}$ is mainly governed by Coulombic interactions via ligand-exchange reactions, this provides the most favourable conditions for sorption (Filius et al. 2000; Chorover and Amistadi 2001; Illés and Tombácz 2004).

At low concentration (i.e. $<20 \mathrm{mgHA} / \mathrm{L}$ ), $\mathrm{HA}$ partially neutralises the positive charges on $\mathrm{Fe}_{2} \mathrm{O}_{3} \mathrm{NPs}$ as shown in the zeta potential profile in Figure 7. Thus, aggregation takes place and extends with increasing $\mathrm{HA}$ concentration to reach a peak at $20 \mathrm{mgHA} / \mathrm{L}$ at which point the zeta potential is reduced to almost zero. At HA concentrations of 10 and $20 \mathrm{mg} / \mathrm{L}$, very large aggregates were formed (see Figure $8 \mathrm{~b}$ ) and due to their rapid sedimentation on the bottom of the vial, FIFFF analysis could not be performed. From the FIFFF fractogram of the mixture of $\mathrm{Fe}_{2} \mathrm{O}_{3} \mathrm{NPs}$ with $5 \mathrm{mg} / \mathrm{L}$ of $\mathrm{HA}$, the following observations can be made. Compared to the fractogram of $\mathrm{Fe}_{2} \mathrm{O}_{3} \mathrm{NPs}$ alone, there is a slight increase in the void peak UV signal which is probably due to the loss of sample during the injection and focusing step and because HA is better adsorbed by UV as shown on the fractogram of HA alone. The second observation is that no apparent shift toward larger retention times is observed because the difference in size obtained from both fractograms is very low. This can be explained by the fact that at $5 \mathrm{mgHA} / \mathrm{L}$, there is a very low amount of HA in the solution; thus, the number of coated nanoparticles is very low and they were not detected during the FFF analysis.

\section{Figure 8}

At higher $\mathrm{HA}$ concentrations (i.e. $\geq 50 \mathrm{mg} / \mathrm{L}$ ), the surface of the $\mathrm{Fe}_{2} \mathrm{O}_{3} \mathrm{NPs}$ becomes negatively charged (i.e. -27.1 $\mathrm{mV}$ at $50 \mathrm{mgHA} / \mathrm{L}$, Figure 7) providing electrostatic stabilisation of the particles and reducing their aggregation (i.e. from almost $1700 \mathrm{~nm}$ at $20 \mathrm{mgHA} / \mathrm{L}$ to $85.2 \mathrm{~nm}$ at $50 \mathrm{mgHA} / \mathrm{L}$ as measured by DLS as shown in Figure 8 b). A significant increase in the void peak UV signal can be observed on the FFF fractograms of $50 \mathrm{mgHA} / \mathrm{L}$ and $100 \mathrm{mgHA} / \mathrm{L}$ (Figure $8 \mathrm{a}$ ). This can be caused by the unadsorbed HA macromolecules. In fact, HA has a molecular weight of $38.7 \mathrm{kDa}$ (as measured by FIFFF - see Figure S4) which corresponds to approximately $1.7 \mathrm{~nm}$ (conversion based on (Shon et al. 
2006)) and is considerably smaller than the $\mathrm{Fe}_{2} \mathrm{O}_{3}$ NPs. Therefore, the applied cross flow was too low to retain the unadsorbed HA molecules, and the elution of unretained HA is indicated by the larger void peak. FFF results also showed a shift toward higher retention times (compared to the FIFFF fractogram of bare $\mathrm{Fe}_{2} \mathrm{O}_{3} \mathrm{NPs}$ ), indicating the formation of small aggregates of coated-particles. The broadening of the peak is probably caused by aggregates having different size and conformation. At a HA concentration of $100 \mathrm{mg} / \mathrm{L}$, both DLS and FFF measurements indicate an increase in the particle size, which is probably due to the formation of larger aggregates. This consideration is supported by the fact that a small fraction of the sample settled on the bottom of the vial.

Finally, by comparing DLS and FFF results, it is clear that FFF, as a fractionation method, can provide not only the hydrodynamic diameter of the coated particles but also valuable information on the coating itself. For instance, the FFF results may be used to assess the amount of HA coated onto the nanoparticles by comparing the intensity of the void peak on the fractograms of HA alone and HAcoated $\mathrm{Fe}_{2} \mathrm{O}_{3} \mathrm{NPs}$. This demonstrates the versatility of FFF over conventional size-measurement techniques.

\subsubsection{Stability under realistic conditions of $\mathrm{pH}$ and ionic composition}

The stability of $\mathrm{HA}$-coated $\mathrm{Fe}_{2} \mathrm{O}_{3} \mathrm{NPs}$ was tested under realistic environmental conditions (i.e. $\mathrm{pH} 7$, $10 \mathrm{mM} \mathrm{NaCl}$ and $0.5 \mathrm{mM} \mathrm{CaCl}_{2}$ ) to verify whether or not this coating could be used effectively in the field. Figure 9 shows the FFF and DLS results for the stability study of a mixture of $\mathrm{Fe}_{2} \mathrm{O}_{3} \mathrm{NPs}(200$ $\mathrm{mg} / \mathrm{L}$ ) coated by HA (50 mg/L).

Compared to bare $\mathrm{Fe}_{2} \mathrm{O}_{3} \mathrm{NPs}, \mathrm{HA}$-coated $\mathrm{Fe}_{2} \mathrm{O}_{3} \mathrm{NPs}$ were less affected by an increase in $\mathrm{pH}$ and were much more stable under neutral $\mathrm{pH}$ conditions. In fact, for the bare nanoparticles, an increase in $\mathrm{pH}$ to $\mathrm{pH} 7$ (i.e. the $\mathrm{PZC}$ ) resulted in extensive aggregation with the formation of large aggregates that were thirty-five times larger than at $\mathrm{pH} 4$ (Figure 9b). However, when the nanoparticles were coated with $\mathrm{HA}$, the same increase in $\mathrm{pH}$ resulted in a size increase of less than $15 \%$. This is most likely due to the negatively charged $\mathrm{HA}$ layer on the $\mathrm{Fe}_{2} \mathrm{O}_{3} \mathrm{NPs}$ surface which prevents particles from aggregating through electrostatic repulsion. Moreover, the macromolecular layer can also provide steric stabilisation by causing entropically unfavourable conditions when the particles come closer to one another (Tiller and O'Melia 1993; Illés and Tombácz 2004).

\section{Figure 9}

Regarding the effect of $\mathrm{NaCl}$ on the stability of $\mathrm{HA}$-coated $\mathrm{Fe}_{2} \mathrm{O}_{3} \mathrm{NPs}$, FFF and DLS results (cf. Figure 9) showed that increasing the $\mathrm{NaCl}$ concentration to $10 \mathrm{mM}$ does not result in aggregation or sedimentation of the sample in comparison to bare $\mathrm{Fe}_{2} \mathrm{O}_{3} \mathrm{NPs}$. In fact, it has been demonstrated in previous studies (Illés and Tombácz 2004; Hajdú et al. 2009) that HA-coated $\mathrm{Fe}_{2} \mathrm{O}_{3} \mathrm{NPs}$ are more stable under high $\mathrm{NaCl}$ concentration due to the electrosteric stabilisation providing by HA coating.

In the presence of $\mathrm{CaCl}_{2}$ at $0.5 \mathrm{mM}, \mathrm{HA}$-coated $\mathrm{Fe}_{2} \mathrm{O}_{3} \mathrm{NPs}$ became unstable and formed large aggregates (greater than $500 \mathrm{~nm}$ when measured by DLS). The effect of increasing the $\mathrm{CaCl}_{2}$ concentration on FFF results is that no peaks were observed, which is most likely to be the results of aggregation and consequently much longer retention times. This aggregation behaviour could be attributed to the formation of complexes between $\mathrm{Ca}^{2+}$ and $\mathrm{HA}$, which neutralises the negative charge imparted by the $\mathrm{HA}$ coating on the $\mathrm{Fe}_{2} \mathrm{O}_{3} \mathrm{NPs}$ and thus, reduces the electrostatic stabilisation 
which previously arose between the coated nanoparticles. In addition, the presence of $\mathrm{Ca}^{2+}$ cations may promote the formation of complexes $\mathrm{Fe}_{2} \mathrm{O}_{3} \mathrm{NPs}-\mathrm{HA}-\mathrm{Ca}^{2+}-\mathrm{HA}-\mathrm{Fe}_{2} \mathrm{O}_{3} \mathrm{NPs}$ (Chen et al. 2006). It has also been reported that other alkaline earth metal divalent cations such $\mathrm{Ba}^{2+}$ and $\mathrm{Sr}^{2+}$ could accelerate hematite aggregate growth at very low concentrations, whereas $\mathrm{Mg}^{2+}$ showed no effect on aggregation even at high concentrations (Chen et al. 2007).

\section{Conclusions}

The stability of both coated and uncoated $\mathrm{Fe}_{2} \mathrm{O}_{3} \mathrm{NPs}$ has been investigated under different environmental conditions by using several analytical techniques and a theoretical method. The need for a multi-method approach has been demonstrated by highlighting the limitations of each method. For instance, one of the limitations of DLS is the polydispersity of the sample which leads to an overestimation of the average particle size. With FFF, limitations arise from the interaction between the membrane and the particles; furthermore the $\mathrm{pH}$ dependent changes in the surface charge of the NPs, which controls the interaction with membrane, may limit the suitability of latex beads as references for particle size. Therefore, the use of FFF with mobile phases mimicking environmentally relevant conditions may not provide definitive answers in terms of particle size as in this case most measurements will not be made using an optimised mode of operation. However, the versatility of FFF was demonstrated for the characterisation of $\mathrm{HA}$-coated $\mathrm{Fe}_{2} \mathrm{O}_{3} \mathrm{NPs}$ by providing valuable information on the adsorption of $\mathrm{HA}$ onto $\mathrm{Fe}_{2} \mathrm{O}_{3} \mathrm{NPs}$. Finally, the DLVO modelling approach is useful for the interpretation of the experimental results, but cannot predict the size of the aggregates. The presence of large aggregates (i.e. above $1 \mu \mathrm{m}$ ) and sedimentation of these aggregates during the analysis were also a significant limitation to the collection of accurate and reliable data. Therefore, this study shows that it is essential to deploy a number of analytical and theoretical techniques to investigate the behaviour of NPs. Other analytical methods that can measure the size of aggregates in this size range with greater accuracy (e.g. low-angle laser light scattering (LALLS) techniques) should also be considered.

The $\mathrm{pH}$ and ionic strength are important environment conditions that need to be carefully considered before releasing nanoparticles into the environment. In the case of $\mathrm{Fe}_{2} \mathrm{O}_{3} \mathrm{NPs}$, commonly encountered soil and groundwater conditions (i.e. $\mathrm{pH} \mathrm{6-8}$ and high ionic strength) can induce extensive aggregation and can thus considerably reduce their mobility and reactivity once injected into subsurface environments. Finding solutions to reduce or suppress particle aggregation is therefore crucial in optimising remediation strategies using these materials. Surface coating is one of the preferred methods used to enhance the stability of the $\mathrm{Fe}_{2} \mathrm{O}_{3} \mathrm{NPs}$. The choice of surface modifier is important and this will depend on the soil conditions and the target contaminants. This study has demonstrated the performance of DOM as a surface coating under conditions similar to the natural soil environment. DOM-coated nanoparticles were observed to show higher stability than naked $\mathrm{Fe}_{2} \mathrm{O}_{3} \mathrm{NPs}$ under some conditions. Aggregation and stabilisation have significant effects on the environmental transport, reactivity and fate of the released nanoparticles and especially on the transport of low-solubility contaminants in subsurface waters. Increased stabilisation will result in better transport and reactivity in the subsurface but may also increase contaminant transportation. Development of modellings on the behaviour of MNPs in the subsurface is still needed but restrained by the lack of data under relevant environmental conditions. 
This research was funded by the Cooperative Research Centre for Contamination Assessment and Remediation of the Environment (CRC CARE). Enzo Lombi acknowledges the Australian Research Council's support through a Future Fellowship grant (FT100100337).

\section{References}

Aiken, G. R., D. M. McKnight, et al. (1985). Humic substances in soil, sediment, and water: geochemistry, isolation and characterization, John Wiley \& Sons.

Alowitz, M. J. and M. M. Scherer (2002). "Kinetics of nitrate, nitrite, and $\mathrm{Cr}(\mathrm{vi})$ reduction by iron metal." Environmental Science and Technology 36(3): 299-306.

Baalousha, M. (2009). "Aggregation and disaggregation of iron oxide nanoparticles: Influence of particle concentration, $\mathrm{pH}$ and natural organic matter." Science of the Total Environment 407(6): 2093-2101.

Baalousha, M., A. Manciulea, et al. (2008). "Aggregation and surface properties of iron oxide nanoparticles: Influence of pH and natural organic matter." Environmental Toxicology and Chemistry 27(9): 1875-1882.

Chen, J., Z. Xiu, et al. (2011). "Effect of natural organic matter on toxicity and reactivity of nano-scale zero-valent iron." Water Research 45(5): 1995-2001.

Chen, K. L., S. E. Mylon, et al. (2006). "Aggregation kinetics of alginate-coated hematite nanoparticles in monovalent and divalent electrolytes." Environmental science \& technology 40(5): 1516-1523.

Chen, K. L., S. E. Mylon, et al. (2007). "Enhanced aggregation of alginate-coated iron oxide (hematite) nanoparticles in the presence of calcium, strontium, and barium cations." Langmuir 23(11): 59205928.

Chorover, J. and M. K. Amistadi (2001). "Reaction of forest floor organic matter at goethite, birnessite and smectite surfaces." Geochimica et Cosmochimica Acta 65(1): 95-109.

Cirtiu, C. M., T. Raychoudhury, et al. (2011). "Systematic comparison of the size, surface characteristics and colloidal stability of zero valent iron nanoparticles pre- and post-grafted with common polymers." Colloids and Surfaces A: Physicochemical and Engineering Aspects 390(1-3): 95104.

Crane, R. A. and T. B. Scott (2012). "Nanoscale zero-valent iron: Future prospects for an emerging water treatment technology." Journal of Hazardous Materials 211-212: 112-125.

Derjaguin, B. and L. Landau (1941). "Theory of the stability of strongly charged lyophobic sols and of the adhesion of strongly charged particles in solutions of electrolytes." Acta Physicochim URSS 14(6): 633-662.

Dickson, D., G. Liu, et al. (2012). "Dispersion and stability of bare hematite nanoparticles: Effect of dispersion tools, nanoparticle concentration, humic acid and ionic strength." Science of the Total Environment 419(0): 170-177. 
Domingos, R. F., M. A. Baalousha, et al. (2009). "Characterizing manufactured nanoparticles in the environment: multimethod determination of particle sizes." Environmental science \& technology 43(19): 7277-7284.

Dubascoux, S., F. Von Der Kammer, et al. (2008). "Optimisation of asymmetrical flow field flow fractionation for environmental nanoparticles separation." Journal of Chromatography A 1206(2): 160-165.

Elimelech, M., X. Jia, et al. (1998). Particle deposition and aggregation: measurement, modelling and simulation Woburn, Massachusetts Butterworth-Heinemann 440.

Elliott, D. W. and W. X. Zhang (2001). "Field assessment of nanoscale bimetallic particles for groundwater treatment." Environmental Science and Technology 35(24): 4922-4926.

Filella, M., J. Zhang, et al. (1997). "Analytical applications of photon correlation spectroscopy for size distribution measurements of natural colloidal suspensions: capabilities and limitations." Colloids and Surfaces A: Physicochemical and Engineering Aspects 120(1): 27-46.

Filius, J. D., D. G. Lumsdon, et al. (2000). "Adsorption of fulvic acid on goethite." Geochimica et Cosmochimica Acta 64(1): 51-60.

Giddings, J. C. (2000). Field flow fractionation handbook Chapter 1: The field-flow fractionation family: Underlying principles, Wiley-interscience.

Hajdú, A., E. Illés, et al. (2009). "Surface charging, polyanionic coating and colloid stability of magnetite nanoparticles." Colloids and Surfaces A: Physicochemical and Engineering Aspects 347(13): 104-108.

Hassellöv, M. and R. Kaegi (2009). Environmental and Human Health Effects of Nanoparticles. Chichester, Wiley.

He, F. and D. Zhao (2007). "Manipulating the size and dispersibility of zerovalent iron nanoparticles by use of carboxymethyl cellulose stabilizers." Environmental Science and Technology 41(17): 62166221.

He, F., D. Zhao, et al. (2007). "Stabilization of Fe - Pd nanoparticles with sodium carboxymethyl cellulose for enhanced transport and dechlorination of trichloroethylene in soil and groundwater." Industrial and Engineering Chemistry Research 46(1): 29-34.

He, Y. T., J. Wan, et al. (2008). "Kinetic stability of hematite nanoparticles: the effect of particle sizes." Journal of Nanoparticle Research 10(2): 321-332.

Hong, S. and M. Elimelech (1997). "Chemical and physical aspects of natural organic matter (NOM) fouling of nanofiltration membranes." Journal of Membrane Science 132(2): 159-181.

Hu, J.-D., Y. Zevi, et al. (2010). "Effect of dissolved organic matter on the stability of magnetite nanoparticles under different $\mathrm{pH}$ and ionic strength conditions." Science of the Total Environment 408(16): 3477-3489. 
Illes, E. and E. Tombácz (2006). "The effect of humic acid adsorption on pH-dependent surface charging and aggregation of magnetite nanoparticles." Journal of Colloid and Interface Science 295(1): 115-123.

Illés, E. and E. Tombácz (2004). "The role of variable surface charge and surface complexation in the adsorption of humic acid on magnetite." Colloids and Surfaces A: Physicochemical and Engineering Aspects 230(1-3): 99-109.

Jortner, J. and C. N. R. Rao (2002). "Nanostructured advanced materials. Perspectives and directions." Pure and Applied Chemistry 74(9): 1491-1506.

Kanel, S. R., B. Manning, et al. (2005). "Removal of arsenic(III) from groundwater by nanoscale zerovalent iron." Environmental Science and Technology 39(5): 1291-1298.

Lead, J. R. and K. J. Wilkinson (2006). "Aquatic colloids and nanoparticles: current knowledge and future trends." Environmental Chemistry 3(3): 159-171.

Liu, J., Z. Zhao, et al. (2008). "Coating Fe3O4 magnetic nanoparticles with humic acid for high efficient removal of heavy metals in water." Environmental Science \& Technology 42(18): 6949-6954.

Liu, Y., S. A. Majetich, et al. (2005). "TCE dechlorination rates, pathways, and efficiency of nanoscale iron particles with different properties." Environmental Science and Technology 39(5): 1338-1345.

Maurice, P. and K. Namjesnik-Dejanovic (1999). "Aggregate structures of sorbed humic substances observed in aqueous solution." Environmental Science \& Technology 33(9): 1538-1541.

Murphy, E. M., J. M. Zachara, et al. (1990). "Influence of mineral-bound humic substances on the sorption of hydrophobic organic compounds." Environmental science \& technology 24(10): 15071516.

Mylon, S. E., K. L. Chen, et al. (2004). "Influence of natural organic matter and ionic composition on the kinetics and structure of hematite colloid aggregation: Implications to iron depletion in estuaries." Langmuir 20(21): 9000-9006.

Phenrat, T., H. J. Kim, et al. (2009). "Particle size distribution, concentration, and magnetic attraction affect transport of polymer-modified $\mathrm{Fe} 0$ nanoparticles in sand columns." Environmental Science \& Technology 43(13): 5079-5085.

Phenrat, T., G. Lowry, et al. (2009). "Physicochemistry of polyelectrolyte coatings that increase stability, mobility, and contaminant specificity of reactive nanoparticles used for groundwater remediation." Nanotechnology Applications for Clean Water: 249-267.

Phenrat, T., N. Saleh, et al. (2007). "Aggregation and sedimentation of aqueous nanoscale zerovalent iron dispersions." Environmental Science and Technology 41(1): 284-290.

Phuntsho, S., H. Shon, et al. (2011). "Assessing membrane fouling potential of humic acid using flow field-flow fractionation." Journal of Membrane Science 373(1-2): 64-73.

Ponder, S. M., J. G. Darab, et al. (2000). "Remediation of $\mathrm{Cr}(\mathrm{VI})$ and $\mathrm{Pb}(\mathrm{II})$ aqueous solutions using supported, nanoscale zero-valent iron." Environmental Science and Technology 34(12): 2564-2569. 
Quinn, J., C. Geiger, et al. (2005). "Field demonstration of DNAPL dehalogenation using emulsified zero-valent iron." Environmental Science and Technology 39(5): 1309-1318.

Saleh, N., H. J. Kim, et al. (2008). "lonic strength and composition affect the mobility of surfacemodified $\mathrm{Fe} 0$ nanoparticles in water-saturated sand columns." Environmental Science \& Technology 42(9): 3349-3355.

Saleh, N., T. Phenrat, et al. (2005). "Adsorbed triblock copolymers deliver reactive iron nanoparticles to the oil/water interface." Nano letters 5(12): 2489-2494.

Saleh, N., K. Sirk, et al. (2007). "Surface modifications enhance nanoiron transport and NAPL targeting in saturated porous media." Environmental Engineering Science 24(1): 45-57.

Schrick, B., B. W. Hydutsky, et al. (2004). "Delivery vehicles for zerovalent metal nanoparticles in soil and groundwater." Chemistry of Materials 16(11): 2187-2193.

Shon, H. K., S. Puntsho, et al. (2009). "A study on the influence of ionic strength on the elution behaviour of membrane organic foulant using advanced separation tools." Desalination and Water Treatment 11(1-3): 38-45.

Shon, H. K., S. Vigneswaran, et al. (2006). "Effect of partial flocculation and adsorption as pretreatment to ultrafiltration." AIChE Journal 52(1): 207-216.

Sirk, K. M., N. B. Saleh, et al. (2009). "Effect of adsorbed polyelectrolytes on nanoscale zero valent iron particle attachment to soil surface models." Environmental Science \& Technology 43(10): 38033808.

Sun, Y.-P., X.-q. Li, et al. (2006). "Characterization of zero-valent iron nanoparticles." Advances in Colloid and Interface Science 120(13): 47-56.

Takahashi, K., H. Kato, et al. (2008). "Precise measurement of the size of nanoparticles by dynamic light scattering with uncertainty analysis." Particle \& Particle Systems Characterization 25(1): 31-38.

Tiller, C. L. and C. R. O'Melia (1993). "Natural organic matter and colloidal stability: Models and measurements." Colloids and Surfaces A: Physicochemical and Engineering Aspects 73(0): 89-102.

Tiraferri, A., K. L. Chen, et al. (2008). "Reduced aggregation and sedimentation of zero-valent iron nanoparticles in the presence of guar gum." Journal of Colloid and Interface Science 324(1-2): 71-79.

Tombácz, E., Z. Libor, et al. (2004). "The role of reactive surface sites and complexation by humic acids in the interaction of clay mineral and iron oxide particles." Organic Geochemistry 35(3): 257267.

Verwey, E. and J. T. G. Overbeek (1948). "Theory of the stability of lyophobic colloids." Amserdam: Elsevier.

Verwey, E. J. W. (1947). "Theory of the stability of lyophobic colloids." The Journal of Physical Chemistry 51(3): 631-636.

Wang, C.-B. and W.-X. Zhang (1997). "Synthesizing nanoscale iron particles for rapid and complete dechlorination of TCE and PCBs." Environmental Science \& Technology 31(7): 2154-2156. 
703 Zhang, W.-X. (2003). "Nanoscale iron particles for environmental remediation: An overview." Journal 704 of Nanoparticle Research 5: 323-332.

705

706

707

708

709

710

711

Zhang, W.-x., C.-B. Wang, et al. (1998). "Treatment of chlorinated organic contaminants with nanoscale bimetallic particles." Catalysis Today 40(4): 387-395.

Zhang, Y., Y. Chen, et al. (2008). "Stability of commercial metal oxide nanoparticles in water." Water Research 42(8-9): 2204-2212. 
714 Figure 1: (a) SEM image of $\mathrm{Fe}_{2} \mathrm{O}_{3} \mathrm{NPs}(50 \mathrm{mg} / \mathrm{L} ; \mathrm{pH} 3)$ and (b) particle size distribution of the same 715 sample determined from SEM images.

716 Figure 2: Influence of particle concentration on the Z-average hydrodynamic diameter of $\mathrm{Fe}_{2} \mathrm{O}_{3} \mathrm{NPs}$ 717 at different $\mathrm{pH}$, as measured by DLS.

718 Figure 3: Interaction forces between two spherical Fe2O3NPs (30 nm diameter) as a function of $\mathrm{pH}$ 719 at (a) $10 \mathrm{mg} / \mathrm{L}$ and (b) $200 \mathrm{mg} / \mathrm{L}$ concentration according to the DLVO theory.

720 Figure 4: Interaction forces between two spherical iron oxide nanoparticles ( $30 \mathrm{~nm}$ diameter, 50 $721 \mathrm{mg} / \mathrm{L}$ ) as a function of $\mathrm{pH}$ according to the DLVO theory.

722 Figure 10: FIFFF fractograms of $\mathrm{Fe}_{2} \mathrm{O}_{3} \mathrm{NPs}(50 \mathrm{mg} / \mathrm{L} ; \mathrm{pH} 4)$ at variable ionic strength.

723 Figure 6: Interaction forces between two spherical $\mathrm{Fe}_{2} \mathrm{O}_{3} \mathrm{NPs}(30 \mathrm{~nm}$ diameter; $50 \mathrm{mg} / \mathrm{L} ; \mathrm{pH} 4$ ) at 724 variable ionic strength according to the DLVO theory.

725 Figure 7: Effect of $\mathrm{HA}$ concentration on the zeta potential profile of $\mathrm{Fe}_{2} \mathrm{O}_{3} \mathrm{NPs}$ as a function of $\mathrm{pH}$.

726 Figure 8: (a) FIFFF fractograms and (b) DLS results of $\mathrm{HA}$-coated $\mathrm{Fe}_{2} \mathrm{O}_{3} \mathrm{NPs}$ at variable DOM 727 concentrations (5-100 mg/L).

728 Figure 9: (a) FIFFF fractograms and (b) DLS results of HA-coated $\mathrm{Fe}_{2} \mathrm{O}_{3} \mathrm{NPs}$ ( $50 \mathrm{mg} / \mathrm{L} \mathrm{HA}$ and $200 \mathrm{mg} / \mathrm{L}$ 729 IONPs) at environmentally relevant conditions. 


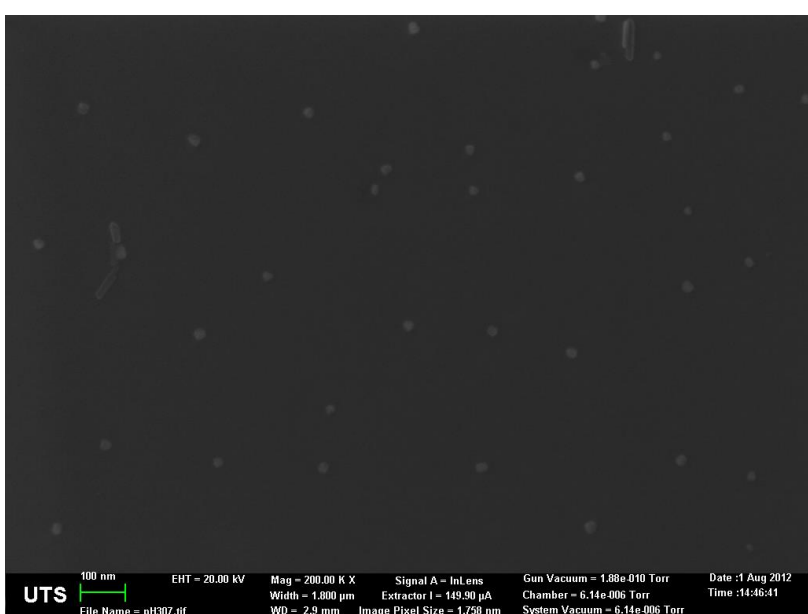

a)

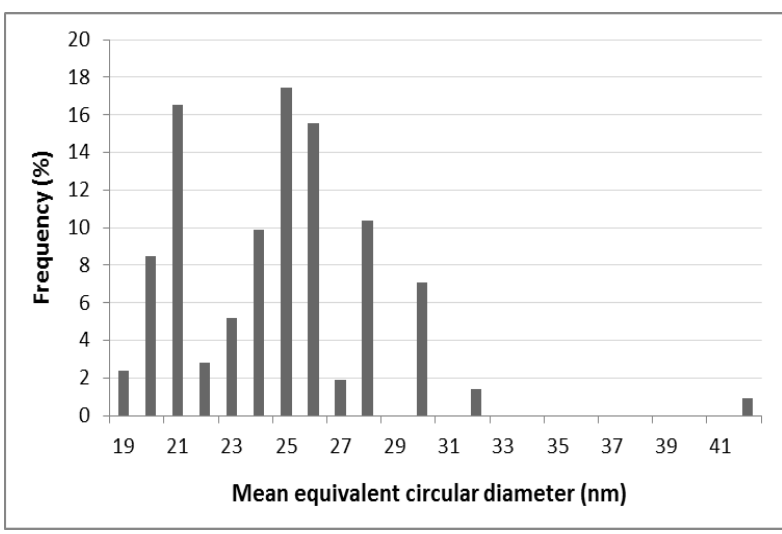

b)

Figure 2

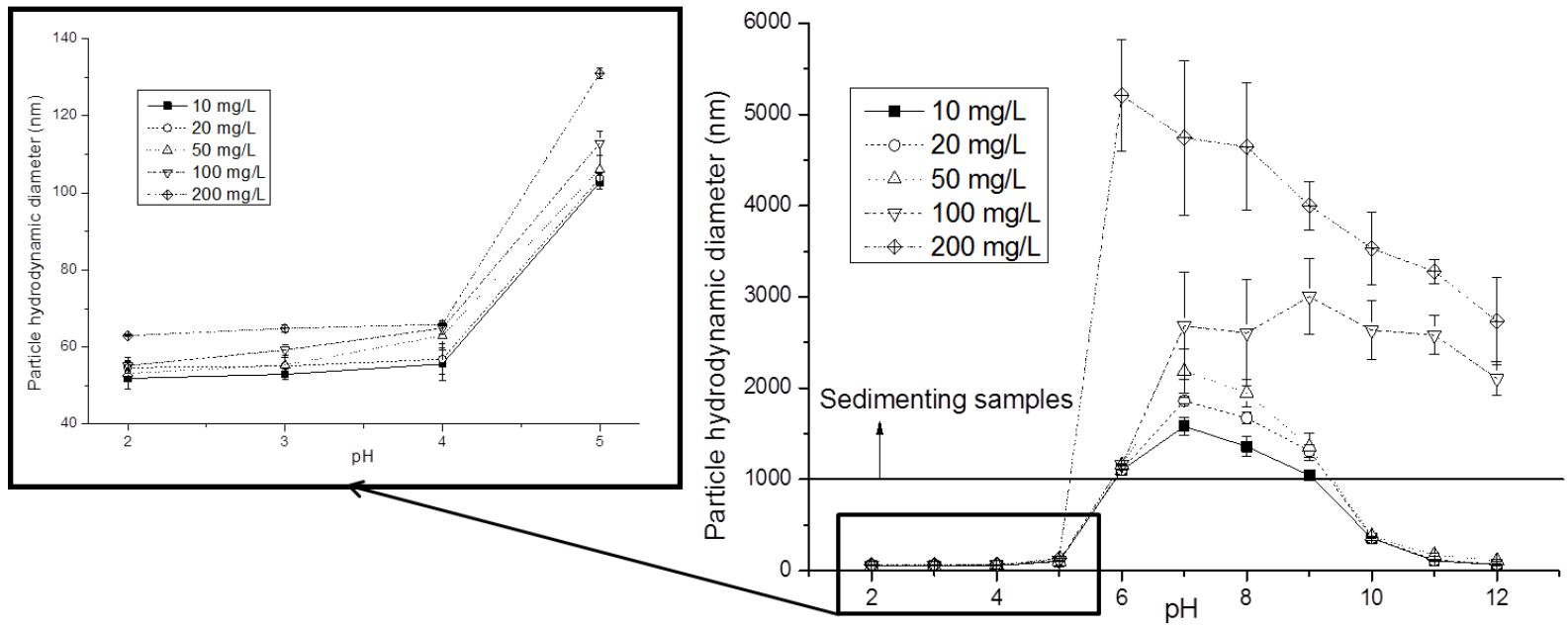

\section{Figure 3}

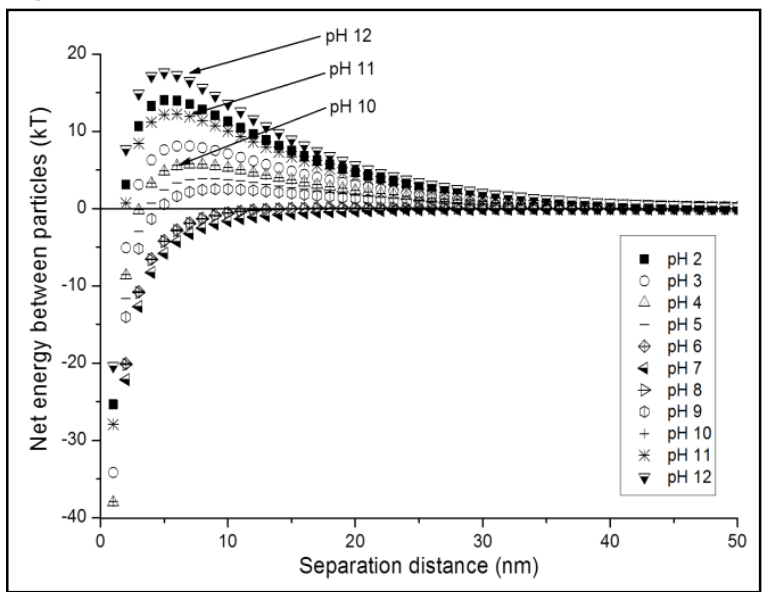

a)

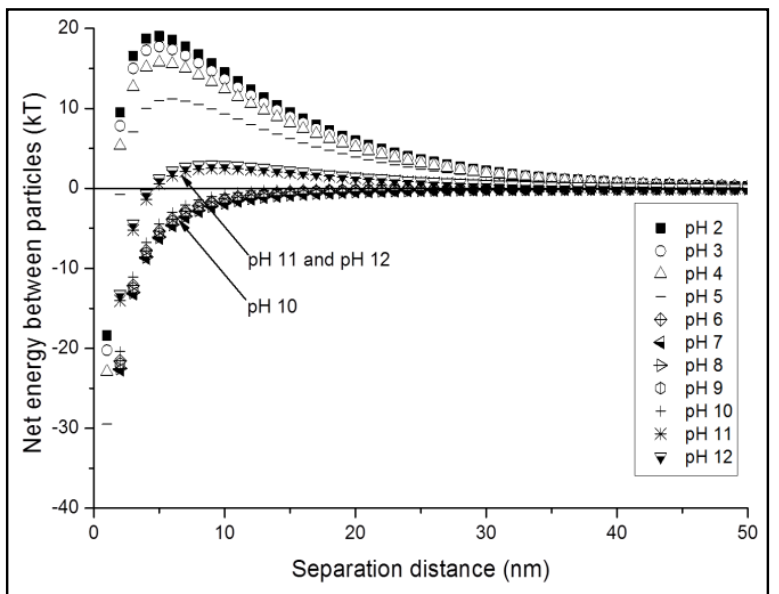

b) 


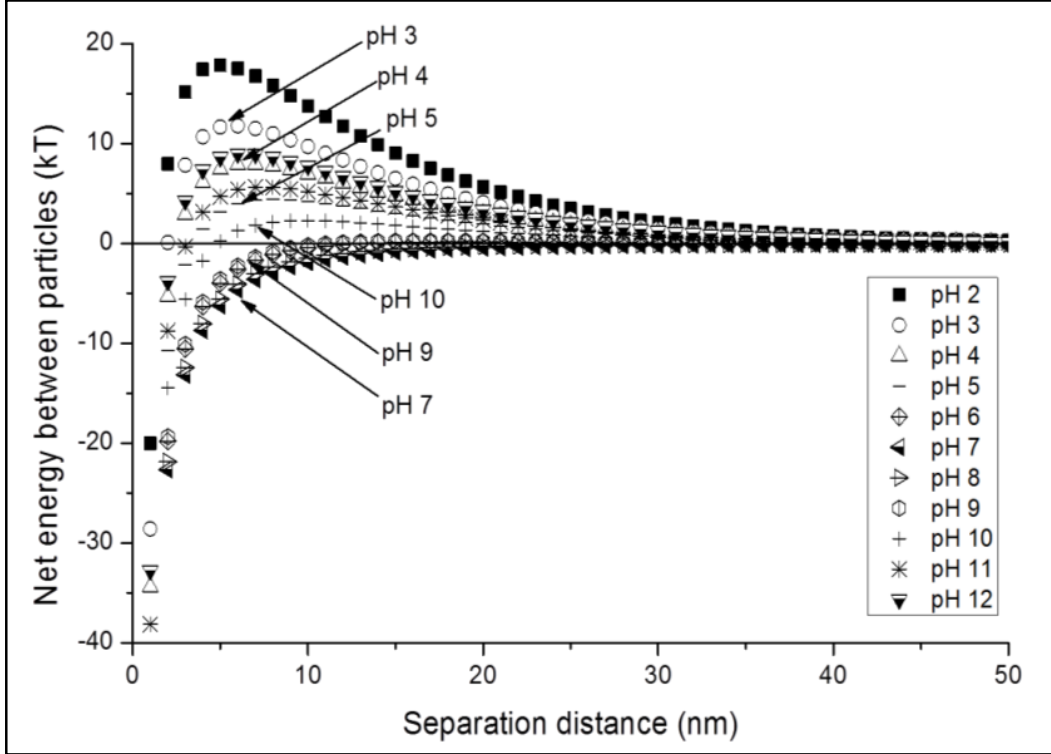

\section{Figure 5}

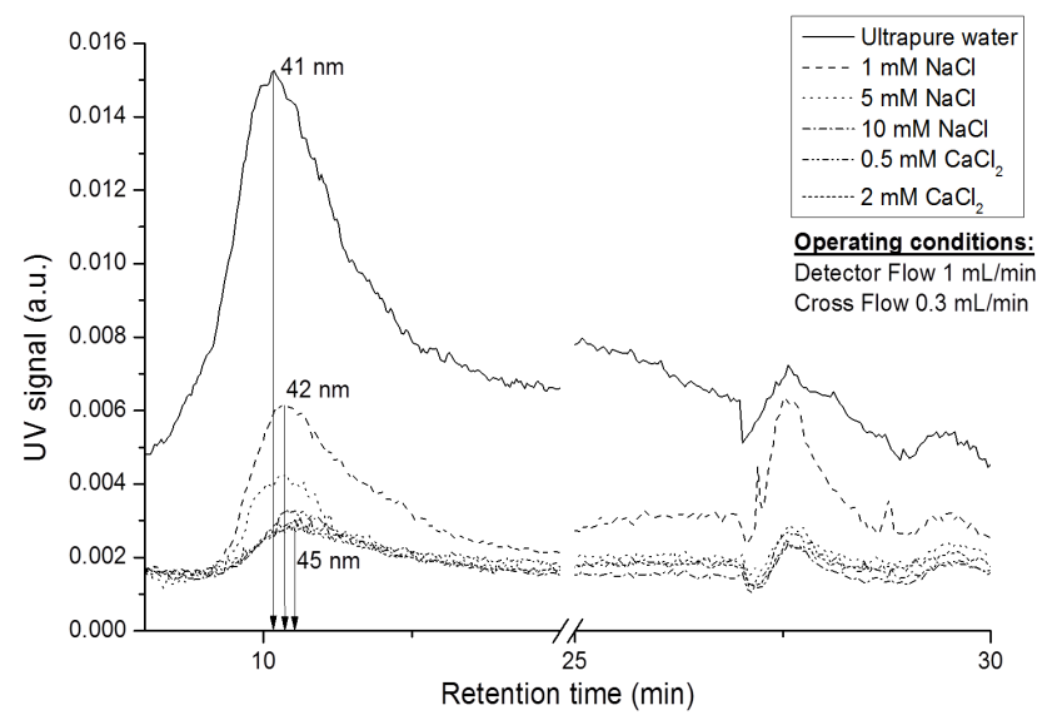

Figure 6

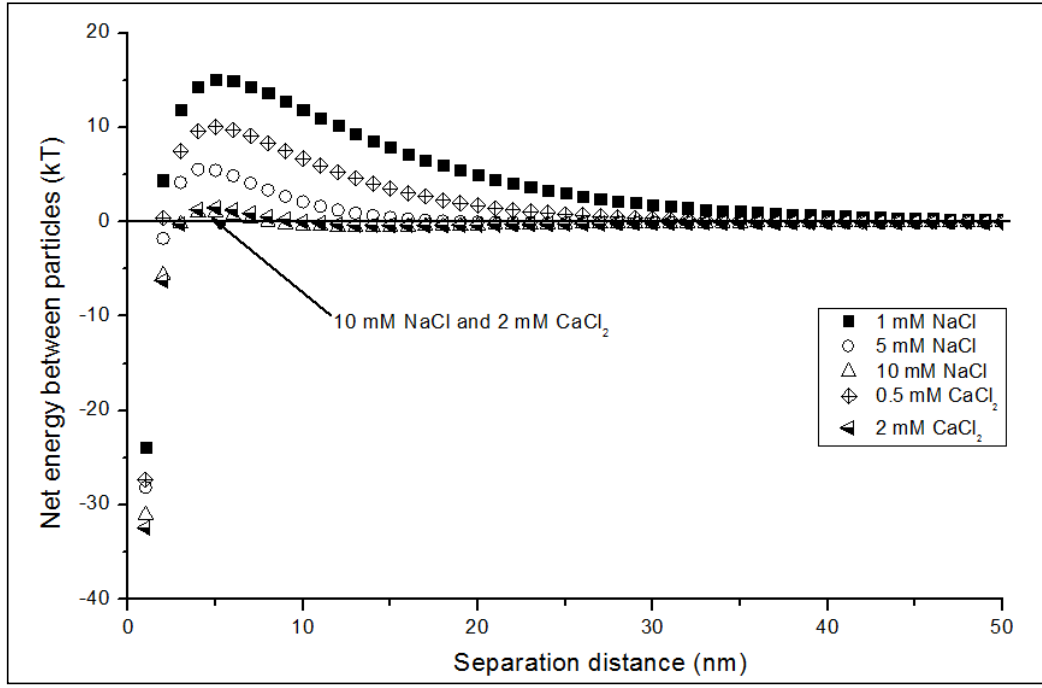




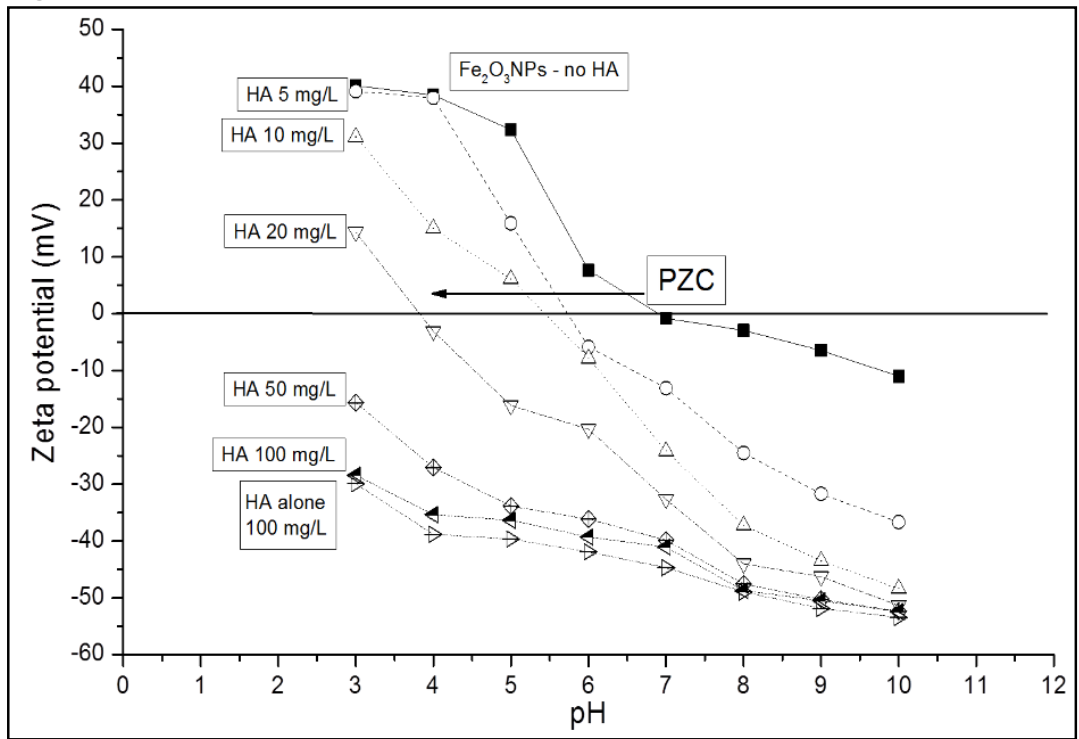

\section{Figure 8}

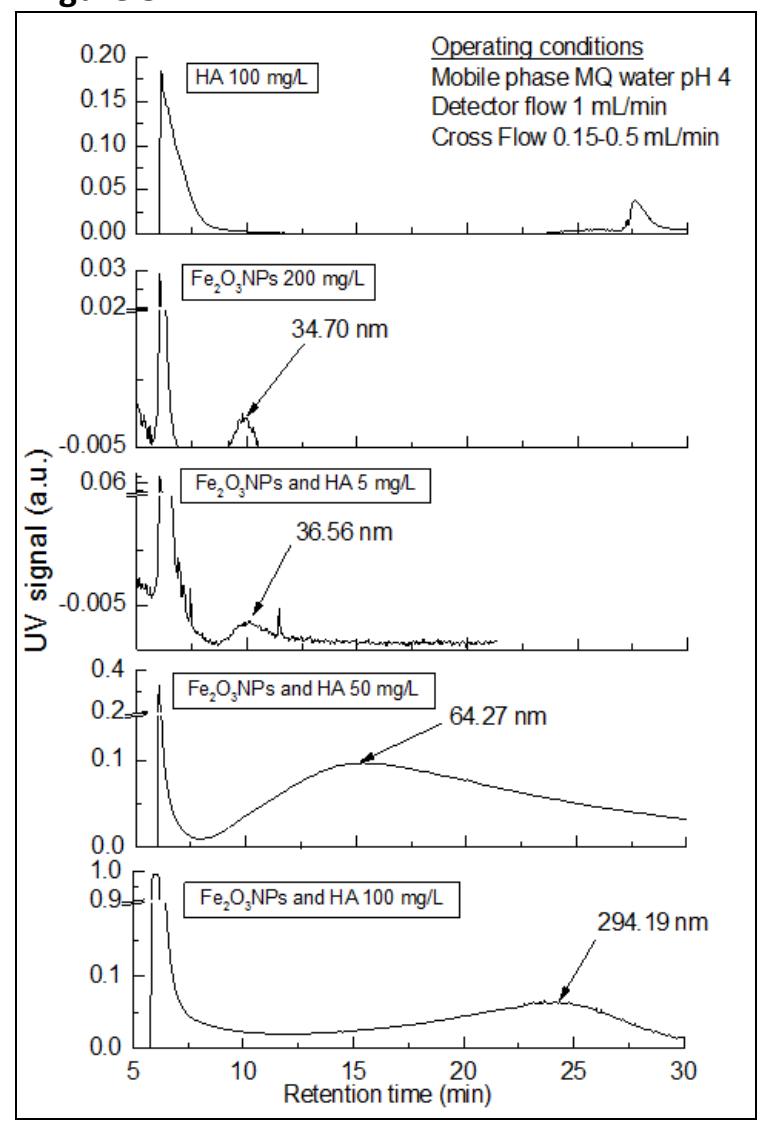

a)

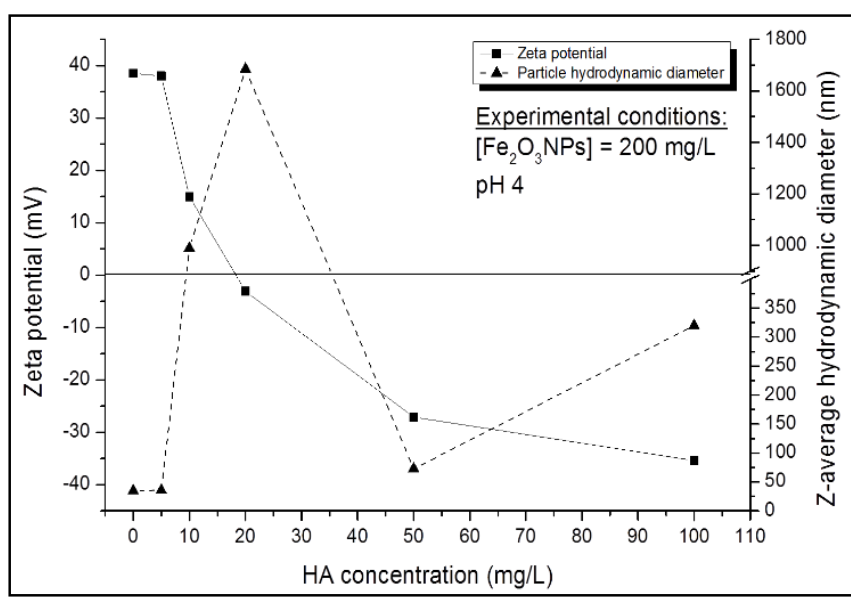

b) 
Figure 9

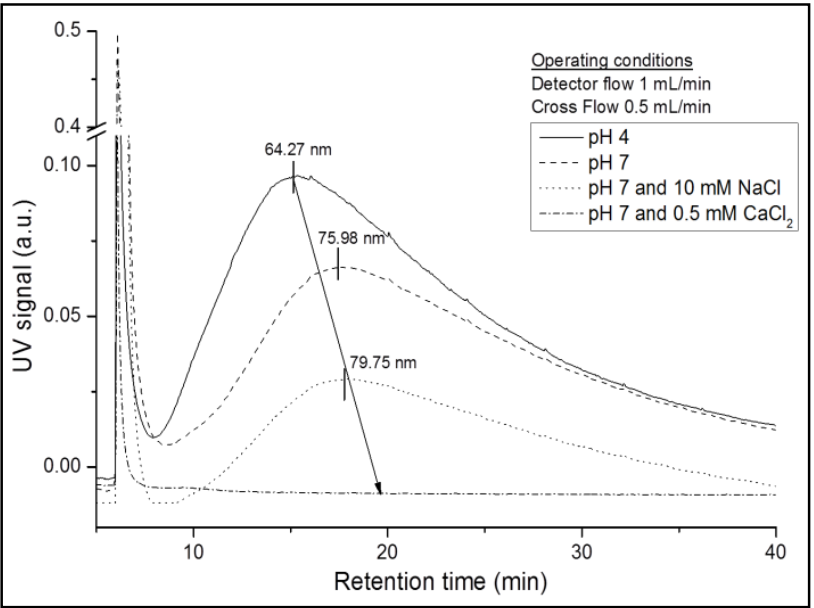

a)

751

752

753

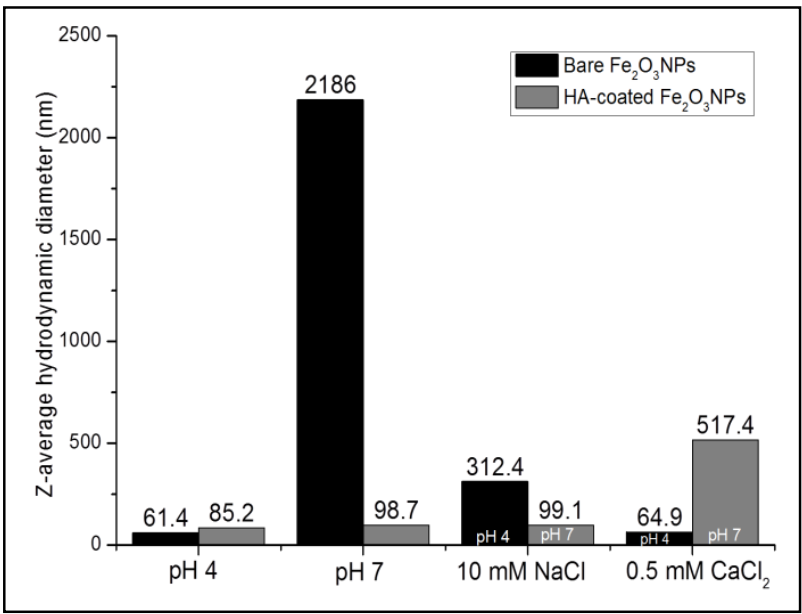

b) 
756

757 Table 1: Summary of the different FFF operating conditions used in this study.

758 Table 2: Summary of the hydrodynamic diameter of $\mathrm{Fe}_{2} \mathrm{O}_{3} \mathrm{NPs}$ at variable $\mathrm{pH}$ as determined from 759 FIFFF/UV, DLS and SEM at $50 \mathrm{mg} / \mathrm{L}$.

760 Table 3: Hydrodynamic diameter (FFF) and Z-average hydrodynamic diameter (DLS) of $\mathrm{Fe}_{2} \mathrm{O}_{3} \mathrm{NPs}$ as a 761 function of ionic strength. 
Table 1

\begin{tabular}{|c|c|c|c|c|}
\hline \multicolumn{2}{|c|}{ Study } & $\begin{array}{l}\text { Channel Flow } \\
\text { (mL/min) }\end{array}$ & $\begin{array}{l}\text { Cross Flow } \\
\text { (mL/min) }\end{array}$ & Mobile phase \\
\hline \multirow{4}{*}{ 1. Effect of pH } & $\mathrm{pH} 3$ & \multirow{4}{*}{1} & 0.5 & Ultrapure water at $\mathrm{pH} 3$ \\
\hline & $\mathrm{pH} 4$ & & 0.3 & Ultrapure water at $\mathrm{pH} 4$ \\
\hline & $\mathrm{pH} 5$ & & \multirow{2}{*}{0.15} & Ultrapure water at $\mathrm{pH} 5$ \\
\hline & $\mathrm{pH} 10$ & & & Ultrapure water at $\mathrm{pH} 10$ \\
\hline \multirow{6}{*}{$\begin{array}{l}\text { 2. Effect of lonic } \\
\text { Strength }\end{array}$} & Ultrapure water & \multirow{6}{*}{1} & \multirow{6}{*}{0.3} & Ultrapure water at $\mathrm{pH} 4$ \\
\hline & $1 \mathrm{mM} \mathrm{NaCl}$ & & & $1 \mathrm{mM} \mathrm{NaCl}$ at $\mathrm{pH} 4$ \\
\hline & $5 \mathrm{mM} \mathrm{NaCl}$ & & & $5 \mathrm{mM} \mathrm{NaCl}$ at $\mathrm{pH} 4$ \\
\hline & $10 \mathrm{mM} \mathrm{NaCl}$ & & & $10 \mathrm{mM} \mathrm{NaCl}$ at $\mathrm{pH} 4$ \\
\hline & $0.5 \mathrm{mM} \mathrm{CaCl}_{2}$ & & & $0.5 \mathrm{mM} \mathrm{CaCl}_{2}$ at $\mathrm{pH} 4$ \\
\hline & $2 \mathrm{mM} \mathrm{CaCl}_{2}$ & & & $2 \mathrm{mM} \mathrm{CaCl}_{2}$ at $\mathrm{pH} 4$ \\
\hline \multirow{5}{*}{$\begin{array}{l}\text { 3. Effect of HA } \\
\text { concentration }\end{array}$} & HA alone $(100 \mathrm{mg} / \mathrm{L})$ & \multirow{5}{*}{1} & \multirow{4}{*}{0.5} & \multirow{5}{*}{ Ultrapure water at $\mathrm{pH} 4$} \\
\hline & $\begin{array}{c}\mathrm{Fe}_{2} \mathrm{O}_{3} \mathrm{NPs} \text { alone }(200 \\
\mathrm{mg} / \mathrm{L})\end{array}$ & & & \\
\hline & $\begin{array}{c}\mathrm{HA} / \mathrm{Fe}_{2} \mathrm{O}_{3} \mathrm{NPs} 5 \\
\mathrm{mgHA} / \mathrm{L}\end{array}$ & & & \\
\hline & $\begin{array}{c}\mathrm{HA} / \mathrm{Fe}_{2} \mathrm{O}_{3} \mathrm{NPs} 50 \\
\mathrm{mgHA} / \mathrm{L}\end{array}$ & & & \\
\hline & $\begin{array}{c}\mathrm{HA} / \mathrm{Fe}_{2} \mathrm{O}_{3} \mathrm{NPs} 100 \\
\mathrm{mgHA} / \mathrm{L}\end{array}$ & & 0.15 & \\
\hline \multirow{4}{*}{$\begin{array}{l}\text { 4. Stability of HA- } \\
\text { coated } \mathrm{Fe}_{2} \mathrm{O}_{3} \mathrm{NPs}\end{array}$} & $\mathrm{pH} 4$ & \multirow{4}{*}{1} & \multirow{4}{*}{0.5} & Ultrapure water at $\mathrm{pH} 4$ \\
\hline & $\mathrm{pH} 7$ & & & Ultrapure water at $\mathrm{pH} 7$ \\
\hline & $\mathrm{pH} 7 / 10 \mathrm{mM} \mathrm{NaCl}$ & & & $10 \mathrm{mM} \mathrm{NaCl}$ at $\mathrm{pH} 7$ \\
\hline & $\mathrm{pH} \mathrm{7/0.5} \mathrm{mM} \mathrm{CaCl} 2$ & & & $0.5 \mathrm{mM} \mathrm{CaCl}_{2}$ at $\mathrm{pH} 7$ \\
\hline
\end{tabular}

765 
Table 2

\begin{tabular}{|c|c|c|c|}
\hline $\mathrm{pH}$ & $\begin{array}{l}\text { FIFFF/UV fractograms } \\
\text { and hydrodynamic diameter (nm) }\end{array}$ & $\begin{array}{l}\text { Z-average hydrodynamic diameter } \\
\text { as determined by DLS (nm) }\end{array}$ & Corresponding SEM images (50 mg/L) \\
\hline 3 & Cross Flow 0.5 mL/min & $55.3 \pm 2.4$ & ATs \\
\hline 4 & $\begin{array}{c}\text { Cetention time (min) } \\
41.42 \pm 0.04\end{array}$ & $63.0 \pm 3.9$ & ATs \\
\hline 5 & $80.33 \pm 0.74$ & $106.1 \pm 3.6$ & UTs \\
\hline 7 & $\begin{array}{r}\text { Samples settled down rapidly to the } b \\
\text { analysed by FIF }\end{array}$ & $\begin{array}{l}\text { ttom of the vial and could not be } \\
F \text { and DLS. }\end{array}$ & 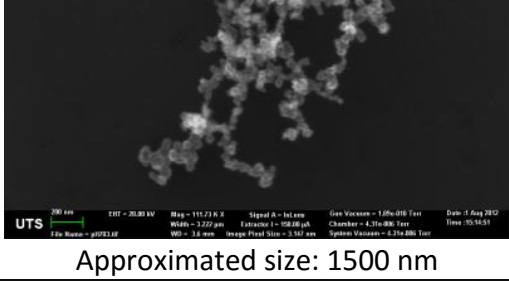 \\
\hline 10 & $\begin{array}{c}\text { Retention time (min) } \\
132.03 \pm 5.85\end{array}$ & $377.5 \pm 3.6$ & UTs \\
\hline
\end{tabular}


Table 3

770

\begin{tabular}{|l|c|c|}
\hline \multirow{2}{*}{$\begin{array}{l}\text { lonic } \\
\text { strength }\end{array}$} & \multicolumn{2}{|c|}{ Particle size (nm) } \\
\cline { 2 - 3 } & FIFFF/UV & DLS \\
\hline $\begin{array}{l}\text { Ultrapure } \\
\text { water }\end{array}$ & $41.4 \pm 0.1$ & $61.4 \pm 1.4$ \\
\hline $\begin{array}{l}1 \quad \mathrm{mM} \\
\mathrm{NaCl}\end{array}$ & $42.3 \pm 0.1$ & $63.2 \pm 3.6$ \\
\hline $\begin{array}{l}5 \mathrm{mM} \\
\mathrm{NaCl}\end{array}$ & $42.8 \pm 1.7$ & $64.4 \pm 5.2$ \\
\hline $\begin{array}{l}10 \mathrm{mM} \\
\mathrm{NaCl}\end{array}$ & $44.7 \pm 2.5$ & $312.4 \pm 10.7$ \\
\hline $\begin{array}{l}0.5 \mathrm{mM} \\
\mathrm{CaCl}\end{array}$ & $44.4 \pm 0.6$ & $64.9 \pm 4.9$ \\
\hline $\begin{array}{l}2 \mathrm{mM} \\
\mathrm{CaCl}_{2}\end{array}$ & $44.8 \pm 2.7$ & $438.7 \pm 18.1$ \\
\hline
\end{tabular}

